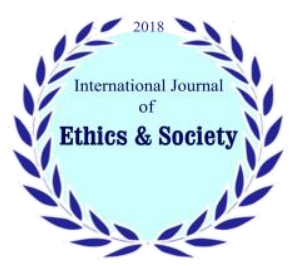

International Journal of Ethics \& Society (IJES)

Journal homepage: $\underline{\text { www.ijethics.com }}$

Vol. 3, No. $3(\mathbf{2 0 2 1})$

(Original article)

\title{
Relationship between Moral Foundations \& Perception of Corporate Social Responsibility
}

\author{
Reza Kaboli ${ }^{a}$, Bahman Banimahd ${ }^{b^{*}}$, Ataollah Mohammadi Molgharani ${ }^{a}$ \\ a) Dept. of Accounting. Sanandaj Branch, Islamic Aqad University, Sanandaj, Iran \\ b) Dept. of Accounting. Karaj Branch, Islamic Azad University, Karaj, Iran
}

\section{Abstract}

Background: Today, social responsibility plays an important role in the success and survival of organizations, also, moral attitudes have a significant impact on corporate social responsibility. Therefore, the aim of this study is to identify the relationship between moral foundations and perception of corporate social responsibility.

Method: The present research is a descriptive study. The statistical population of this study is financial managers of the companies listed in Tehran Stock Exchange. The convenience sampling method is used to select the statistical sample. The research instrument includes two standard questionnaires of moral foundations and perception of corporate social responsibility. Finally, the data extracted from 240 questionnaires were analyzed using Structural Equation Modeling by Lisrel software.

Results: The results confirmed the existence of a positive and significant relationship between moral foundations and perception of social responsibility. In other words, any change in the variable of moral foundations changes all aspects of economic, legal, ethical, and philanthropic corporate social responsibility.

Conclusion: Implementation of corporate social responsibility has many benefits for the society. Therefore, regulatory bodies and decision-making authorities should consider corporate mangers' moral foundations as a factor affecting on corporate social responsibility.

Keywords: Ethics, Moral Foundations, Perception of Social Responsibility

* Corresponding Author: Email: dr.banimahd@gmail.com

Received: 24 Jul 2021

Accepted: 25 Aug 2021

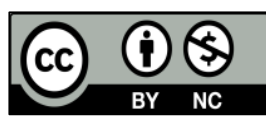

44

Available at: www.ijethics.com
Copyright: C 2021 Banimahd B. et al. Published by Iranian Association of Ethics in Science and Technology This article is an open access article distributed under a Creative Commons Attribution-Noncommercial 4.0 International License. (https://creativecommons.org/licenses/by-nc/4.0/ ). 


\section{Introduction}

The globalization of economy and emergence of multinational companies, the emergence of social and environmental crises and the increasing demand and political pressures for higher transparency of business enterprises have expanded studies on corporate social responsibility in recent years (1). Scholars in corporate social responsibility research have theorized that managerial ethical decision making may influences on corporate social responsibility policies. They claim when a firm is irresponsible in social commitments, it imposes a social cost on their stakeholders and may violate the environment or human rights. This issue could highly affect going concern of firms (2). However, if we consider the definition of corporate social responsibility as an individual or organization's commitment to the society, then, this concept may be defined differently in terms of specific obligations or ethical expectations. Social responsibility defined as the commitment of decision-makers to take actions that also improve the well-being of society, in addition to improve their own interests (3).

In general, the corporate social responsibility refers to the employees' perception of the corporate policies for the implementation of social responsibility, which is defined as a responsibility beyond economic considerations. In corporate social responsibility, the continuity and integrity between the activities and values of the organization are such that the interests of all stakeholders are reflected in the policies and performance of the organization. In other words, organization should always consider itself a part of society, feel more responsible for society, and improve public welfare independently of corporate interests (4).

Although there are different approaches to corporate social responsibilities, researchers believe that Carroll's pyramid of social responsibility could help to resolve these conflicts a lot. Due to its practical nature, this pyramid is more popular in the academic and business worlds. This researcher divided corporate social responsibility into four categories: economic responsibilities, legal responsibilities, ethical responsibilities, and philanthropic responsibilities (5). He believes that at the base of the pyramid, an organization's main goal is to make a profit, which is the main foundation of an organization's activities. The primary responsibility of each firm is to make a profit to ensure its survival and fulfill other responsibilities. There is no legitimacy or security without this component (6).

The second layer of the social responsibility pyramid is legal responsibility. According to this layer of social responsibility, organizations should comply the laws and regulations announced by state and local governments as an operating requirement. In the third dimension of social responsibility, organizations are expected to respect employees, consumers, owners and the community values, norms, principles and consider ethical dignities in their actions and activities (7).

In fact, there is no legal requirement for ethical responsibility, and these measures are the voluntary choices of companies. Finally, there is a discretionary responsibility on top of the pyramid. This is the highest level of responsibility and exceeds expectations. The community expects companies to use their resources to promote social welfare. These responsibilities include activities aimed at creating good organizational citizens by carrying out philanthropic activities to promote the community's wellbeing (6).

Given to above issues, social responsibility is the corporate's commitment and responsibility to society during decision-making. For this reason, the importance of ethics in these decisions is explicit, and disregarding ethical issues and evading social responsibilities will impose a lot of adverse effects on corporate reputation (7).

Result of the studies also show that in most cases, individual factors such as ethical attitude have affected ethical decision-making (8). Corporate social responsibility is an inseparable part of business. Success in business also depends on factors such as organizational culture, economic factors, and corporate ethical climate (9). A study of the relationship between ethics and social responsibility indicates that there is a significant relationship between ethical attitudes and decision making for publishing corporate social responsibility information (10). 
Ethical responsibility can lead the organization to respect social responsibility (11). According to the theory of ethical development, managers' high ethical values reflect their high social responsibility, which is likely to reduce deceptive behaviors (12). The results of a study show that professional ethics directly increases the level of social responsibility and individual accountability (13). In line with these results, other studies' findings indicated a significant and positive relationship between professional ethics and social responsibility and organizational performance $(14,15)$. In general, ethics and ethical values play a significant role in the direction of individual behavior and can affect the ethical decisionmaking process. In recent decades, importance of paying attention to ethics and moral reasoning has become more evident in study of human cognition, and most efforts have been made to find and test comprehensive principles of ethical judgment. One of the relatively new theories in moral psychology is the theories of moral foundations (16).

This theory describes human judgments, values, and ethical behaviors based on moral intuition and emotions (16). Based on this theory, moral judgment is essentially done by five distinct domains. These five fundamental moral foundations include 1) harm/care, 2) fairness/proportionality, 3) ingroup/loyalty, 4) Authority/respect and 5) $\mathrm{Pu}$ rity/Sanctity (17). Harm/care refers to the extent to which an individual highlight and emphasizes the importance of others' trouble. Fairness/ proportionality includes some concepts such as justice and unbiased behaviors. The Intragroup/loyalty component emphasizes orientation to the group and the formation of "we." Authority/respect includes following and respecting powerful figures in a hierarchical system, and finally, Purity/Sanctity is related to hatred of unclean activities, individuals, and objects (18). Each of these components processes a different type of ethical information that ultimately forms the foundations of our ethical judgments before reasoning and consultation (16).

Some findings show that harm/care and fairness/ proportionality are components of moral foundations are significant positively related to responsibility and cognitive flexibility. In fact, these results confirm that different behavioral characteristics of human personality could impact on the decisionmaking process (19). Also, results of a study show when as dogmatism increases in a society, moral foundations are weakened and violence replaces prosperity. In such societies, trust, adjustment and social cooperation will be decreased. (20). In another study, also, is claimed that professional ethics can be an effective and important means to improve commitment and social responsibility (21). Despite various studies on corporate social responsibility, in our opinion, there are a research gap about moral foundation and its effects on social responsibility perceptions in the literatures.

Therefore, the aim of this study is to investigate the relationship between moral foundations and economic, legal, ethical, and optional aspects of corporate social responsibility among financial managers of companies listed in Tehran stock exchange. This study contributes prosocial behavior literatures at the individual level and highlight the role of social psychological attributes such as moral foundations in corporate social responsibility. Hence, we believe that our findings could enhance accounting scholars' insight on firm managers' moral foundations and its roles in corporate social responsibility. 


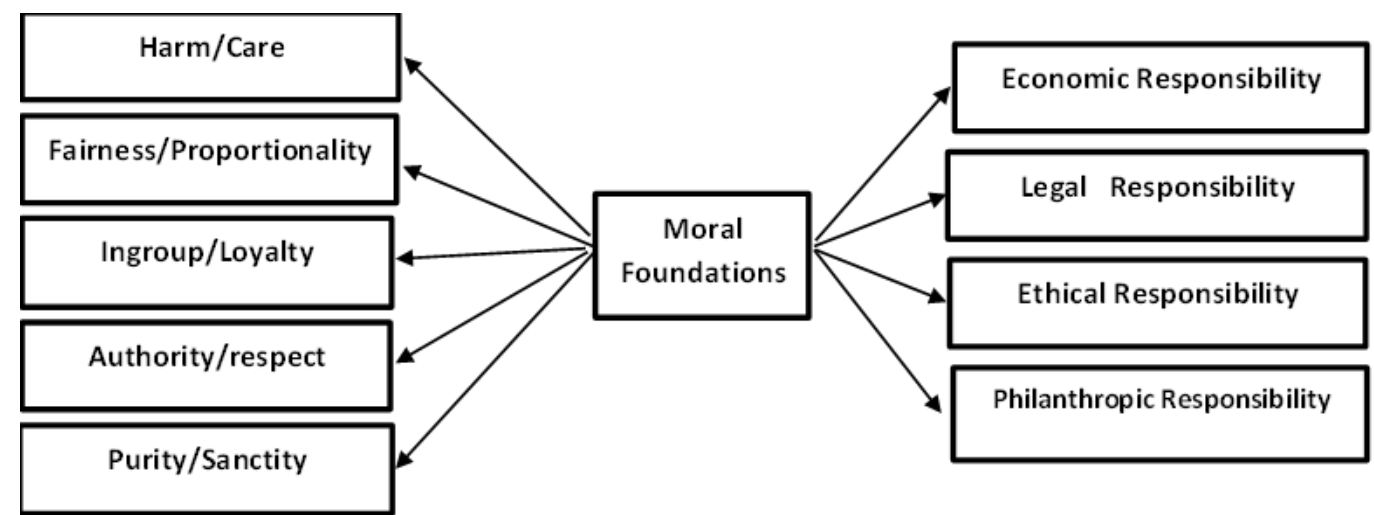

Fig 1: Research Model

\section{Material \& Methods}

This research is applied research. In terms of methodology, it is one of the descriptive studies. Since this research has been conducted in a real environment, i.e., companies listed in Tehran stock exchange, it is considered field research, and the statistical population of the research includes financial managers of companies listed in Tehran stock exchange in 2021. The sample size in this study is 240 peoples. The convenience sampling method was used to select the statistical sample. Demographic characteristics of the sample members showed that 146 participants $(60.8 \%)$ were male and $94(39.2 \%)$ were female. The research instrument is questionnaire. The main questions of the research were standard and used in the previous studies, so the questionnaires were first translated into Persian and then distributed among the statistical sample.

we use Confirmatory Factor Analysis test for validity and reliability of the research variables. Therefore, confirmatory factor analysis was applied using factor loading criteria and Average Variance Extracted (AVE) to measure convergent validity, and also for reliability, a method called Construct Reliability (CR) has been used. The results of validity and reliability test has been shown in table 1 and 2 .

In this study, the dependent variable is "perception of corporate social responsibility," which has been measured through questionnaire (6). This questionnaire consists of 20 questions that measure people's perception of social responsibility from four perspectives of economic responsibilities (questions 1-
5), legal responsibilities (questions 6-10), ethical responsibilities (questions 11-15), and philanthropic responsibilities (questions 16-20).

Respondents determine their agreement or disagreement on each sentence with the 5-point Likert Scale (1- completely agree to 5- completely disagree). The independent variable of "moral foundations" was measured through a standard questionnaire (22).

This questionnaire was developed to evaluate and measure the dimensions of individual morals and contains 32 questions. Questions (1, 7, 12, 17, 23 and 28) measure harm/care component, questions $(2,8,13,18,24$ and 29) measure component of fairness/proportionality, questions $(3,9,14,19,25$ and 30) measure component of ingroup/loyalty, questions $(4,10,15,20,26$ and 31) measure authority/respect component and finally questions $(5,11$, 16, 21, 27 and 32) measure the Purity/Sanctity component of moral foundations.

All questions are scored based on the Likert scale. In this research, both descriptive statistics and inferential statistics methods have been used. First, after collecting the questionnaires, their raw information was summarized in Excel software. Then, after data reduction using descriptive statistics indicators, the respondents' characteristics were described, and finally, the structural equations model was used to analyze the data and test the research hypotheses. 


\section{Results}

In inferential analysis, before testing the hypotheses, we should test the validity and reliability of the research variables using the Confirmatory Factor Analysis test. Therefore, confirmatory factor analysis was applied using factor loading criteria and $\mathrm{Av}$ - erage Variance Extracted (AVE) to measure convergent validity, and also for reliability, a method called Construct Reliability (CR) has been used. Summary of the results of factor analysis and reliability of the research variables in standard and significant mode, then deleting questions with weaker metrics and re-testing with the remaining dimensions are shown in Tables (1) and (2).

Table 1: Results of factor analysis of research variables

\begin{tabular}{|c|c|c|c|c|c|c|}
\hline AVE & Standard Error & t-value & Factor loading & Item & Dimensions & Variables \\
\hline \multirow{3}{*}{0.406533} & 0.48 & 11.36 & 0.72 & Q8 & \multirow[t]{3}{*}{ Fairness/Proportionality } & \multirow{9}{*}{$\begin{array}{l}\text { Moral Founda- } \\
\text { tions }\end{array}$} \\
\hline & 0.59 & 9.91 & 0.64 & Q13 & & \\
\hline & 0.71 & 8.24 & 0.54 & Q18 & & \\
\hline \multirow[t]{2}{*}{0.46665} & 0.39 & 12.52 & 0.78 & $\mathrm{Q}^{9}$ & \multirow[t]{2}{*}{ Ingroup/Loyalty } & \\
\hline & 0.68 & 9.03 & 0.57 & Q14 & & \\
\hline \multirow[t]{2}{*}{0.52425} & 0.24 & 16.72 & 0.87 & Q4 & \multirow[t]{2}{*}{ Authority/Respect } & \\
\hline & 0.71 & 8.20 & 0.54 & Q15 & & \\
\hline \multirow[t]{2}{*}{0.481} & 0.61 & 10.15 & 0.62 & Q5 & \multirow[t]{2}{*}{ Purity/Sanctity } & \\
\hline & 0.42 & 12.72 & 0.76 & Q11 & & \\
\hline \multirow[t]{4}{*}{0.432325} & 0.48 & 11.21 & 0.72 & Q1 & \multirow{4}{*}{$\begin{array}{l}\text { The economic dimension of } \\
\text { social responsibility }\end{array}$} & \multirow{17}{*}{$\begin{array}{l}\text { Corporate social } \\
\text { responsibility }\end{array}$} \\
\hline & 0.31 & 13.14 & 0.83 & Q2 & & \\
\hline & 0.77 & 7.02 & 0.48 & Q3 & & \\
\hline & 0.71 & 8.07 & 0.54 & Q4 & & \\
\hline \multirow[t]{4}{*}{0.40575} & 0.65 & 8.76 & 0.59 & Q6 & \multirow{4}{*}{$\begin{array}{l}\text { The legal dimension of social } \\
\text { responsibility }\end{array}$} & \\
\hline & 0.62 & 9.18 & 0.61 & Q7 & & \\
\hline & 0.48 & 11.09 & 0.72 & Q8 & & \\
\hline & 0.62 & 9.23 & 0.62 & Q9 & & \\
\hline \multirow[t]{4}{*}{0.428025} & 0.52 & 10.88 & 0.69 & Q11 & \multirow{4}{*}{$\begin{array}{l}\text { The ethical dimension of so- } \\
\text { cial responsibility }\end{array}$} & \\
\hline & 0.51 & 10.93 & 0.70 & Q12 & & \\
\hline & 0.67 & 8.71 & 0.58 & Q14 & & \\
\hline & 0.59 & 9.89 & 0.64 & Q15 & & \\
\hline \multirow[t]{5}{*}{0.48202} & 0.71 & 8.24 & 0.54 & Q16 & \multirow{5}{*}{$\begin{array}{l}\text { Philanthropic dimension of } \\
\text { social responsibility }\end{array}$} & \\
\hline & 0.48 & 11.92 & 0.72 & Q17 & & \\
\hline & 0.42 & 12.75 & 0.76 & Q18 & & \\
\hline & 0.50 & 11.67 & 0.71 & Q19 & & \\
\hline & 0.48 & 11.89 & 0.72 & Q20 & & \\
\hline
\end{tabular}

As can be seen, the factor loading of all remaining questions for each variable is more than 0.4 and significant. On the other hand, the mean value of Average Variance Extracted (AVE), which some researchers believe to be higher than $0.4(23)$, is also confirmed. Finally, based on the high composite reliability of 0.6 , it can be claimed that there is internal consistency (24). Then, the research hypotheses were tested.

Table 2- Results of reliability test of research variables

\begin{tabular}{|c|c|c|c|}
\hline Composite Reliability (CR) & Number of questions & Abbreviation & Variable \\
\hline- & 1 & CAR.H & Harm/care \\
\hline 0.669759 & 3 & FAI.R & Fairness/ Proportionality \\
\hline 0.630078 & 2 & LOY.I & Authority/respect \\
\hline 0.676662 & 2 & RE.AU & Purity/Sanctity \\
\hline 0.648991 & 2 & PU.SA & The economic dimension of social responsibility \\
\hline 0.744222 & 4 & Cec & The legal dimension of social responsibility \\
\hline 0.731341 & 4 & Cle & The ethical dimension of social responsibility \\
\hline 0.74841 & 4 & Cet & Philanthropic dimension of social responsibility \\
\hline 0.821287 & 5 & Cph & .
\end{tabular}


Structural Equation Modeling is used to test the research hypothesis. To test the hypotheses, the path coefficient indicates the effect, and the TValue statistic related to the path coefficient indicates that the path coefficient is significant if the $\mathrm{T}$-Value statistic related to the path coefficient is higher than 1.96 or lower than -1.96 . The results of the structural equation modeling method to test the research model in the standard and significance states are shown in Figures $2 \& 3$.

Based on the data inserted in Figures 2 and 3, variable of the moral foundations has a positive relationship with economic, legal, ethical, and philanthropic dimensions of social responsibility $(0.33$, $0.37,0.55$, and 0.28 , respectively).

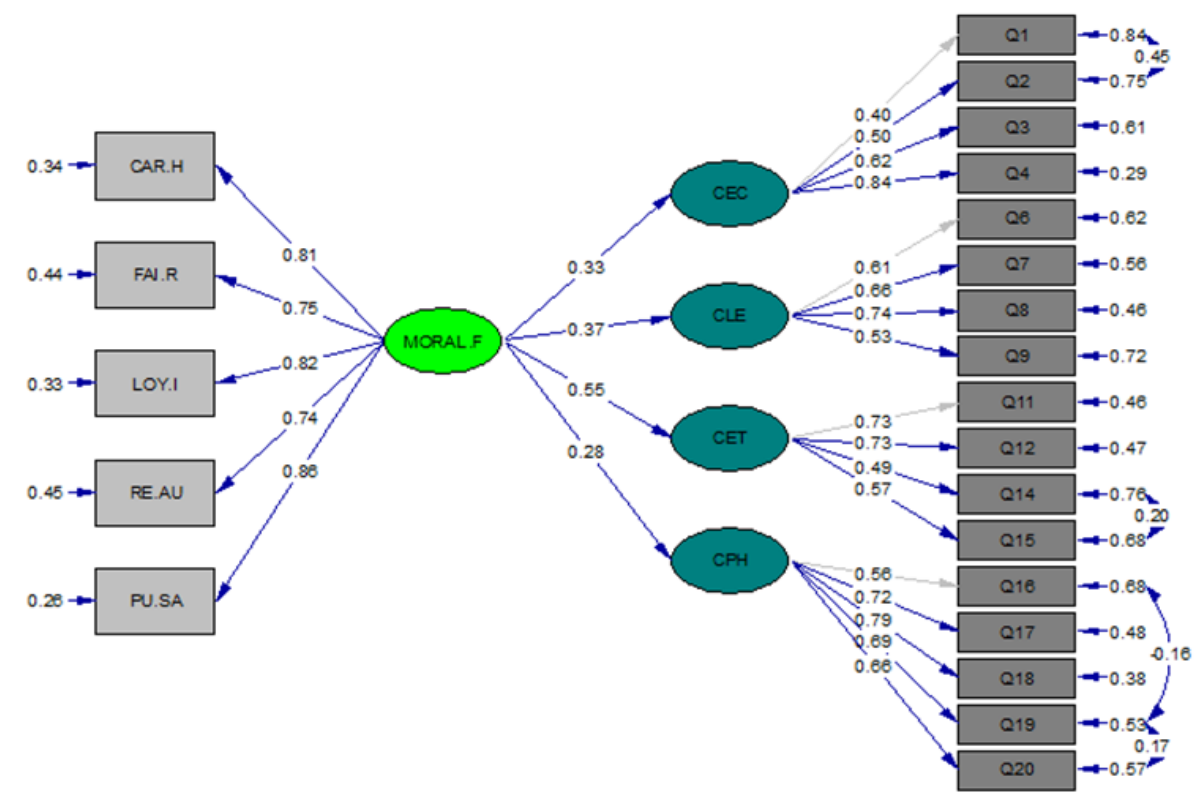

Fig 2: The research model output in standard state

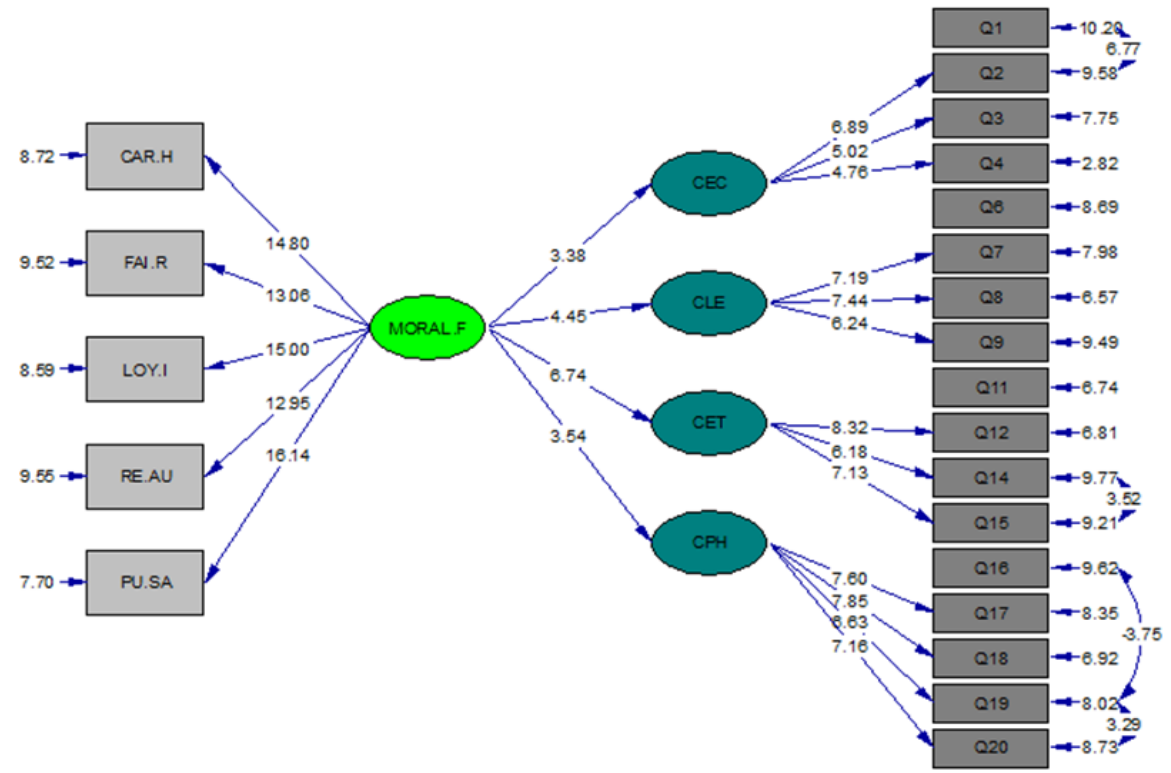

Fig 3: The research model output in significance state 
Since the T-Value statistics of these coefficients are $3.38,4.45,6.74$, and 3.54 , respectively, these values are higher than 1.96 , so these effects are significant. If we consider the data collected from a statistical sample as an estimate of reality, the question arises as to what extent the collected data supports the model that has been theoretically formulated. This key question constitutes the subject of "data fitting with the model, "Considering the efforts made to formulate his theoretical model and collect the data, the researcher expects that data fitting with the model in his research to be acceptable based on scientific criteria (15).

Two basic and important indicators indicating the fitting of the model have been measured in this research and mentioned in Table 3.

\begin{tabular}{|c|c|c|c|}
\hline $\begin{array}{l}\text { Fitting } \\
\text { status }\end{array}$ & $\begin{array}{l}\text { Calcu- } \\
\text { lated val- } \\
\text { ues of the } \\
\text { indices }\end{array}$ & $\begin{array}{l}\text { Recommended } \\
\text { values }\end{array}$ & $\begin{array}{l}\text { Concep- } \\
\text { tual } \\
\text { model fit- } \\
\text { ting indi- } \\
\text { ces }\end{array}$ \\
\hline $\begin{array}{l}\text { Accepta- } \\
\text { ble }\end{array}$ & 2.49064 & Chi Square/df $\leq 3$ & $\begin{array}{l}\text { Chi } \\
\text { Square/df }\end{array}$ \\
\hline $\begin{array}{l}\text { Accepta- } \\
\text { ble }\end{array}$ & 0.079 & 08 RMSEA $\leq 0.1$ & RMSEA \\
\hline
\end{tabular}

According to the above Table, it can be concluded that the tested model has a good fit with the collected data.

\section{Discussion}

The present study investigated the relationship between moral foundations and dimensions of corporate social responsibility based on Carroll's proposed model among financial managers of companies listed in Tehran Stock Exchange. As mentioned before, social responsibility is the commitment and responsibility of the company towards society when making decisions, and undoubtedly, the influence of moral factors on human behavior and decisions is also certain. In this regard, the researchers' previous findings showed that moral responsibility could lead the organization towards social responsibility (11) and the high level of moral values of managers reflects their high social responsibility (12). Moral foundations are a variable explaining ethical reasoning. According to this model, people use social intuition to confirm something that has been achieved before in the moral judgments of real life and ultimately to describe their ethical judgments, values, and behaviors. The research in this field also indicates that the components of moral foundations related to others are positively related to responsibility (19). The results of this study, in line with the findings of other studies, showed that moral foundations are positively and significantly related to all aspects of social responsibility. In fact, although ethical and optional responsibility is beyond the fulfillment of economic and legal obligations and individuals do not think about profit maximization while implementing these responsibilities, it is necessary to observe these responsibilities to prevent social and economic damages, and according to these results, ethical people place more importance on corporate social responsibility, in all aspects. Therefore, based on the results of this study, it is suggested that to evaluate and improve the social responsibility of companies, regulatory bodies, and decision-making authorities, consider the observance of ethical principles and standards more than ever and consider moral foundations as a factor affecting adherence to social responsibility.

On the other hand, considering the impact of moral foundations on judgments and decisionmaking and that cultural factors play a determining role in the prominence of any moral foundation, this theory should be repeated to determine which components are the most important in Iran are used in judgments. Naturally, any research starts as the sketch in the researcher's mind and is nurtured and identified in terms of its domains, dimensions, and methodology, leading to findings and results by collecting the data and analyzing them. Therefore, there may be some obstacles and limitations along, and the main limitation of this research is the use of the questionnaire, which is due to its 
inherent limitations. Based on this limitation, respondents may not be careful when answering questions or their conditions, and moods may change under the environmental situations so that they do not understand the answers correctly and challenge generalization of the results to the population, which is beyond the control of the researcher. Another limitation of this study was the lack of research in this field in the country, which limited the researcher to study the background in Iran and compare the results with local studies.

\section{Conclusion}

In recent decades, the concept of corporate social responsibility has attracted much attention of researchers, and paying attention to social interests has also become important beyond economic and legal responsibilities. Today, this concept is one of the most important issues in the academic environment and business world. Several managers pay attention to it in their decisions voluntarily or compulsorily because the implementation of social responsibility brings several obvious and hidden benefits to the community business enterprises. Since the observance of social responsibility includes behavioral and ethical standards and factors such as culture, customs, attitude, etc., can affect it. Therefore, identifying the factors affecting people's perception of social responsibility can effectively improve the sense of responsibility and accountability in companies by increasing awareness in this field. Based on the results of this study, moral foundations have a positive relationship with economic, legal, ethical, and optional aspects of social responsibility. Since the managers and employees decide to observe different aspects of social responsibility, therefore, having ethical programs and strengthening ethical attitudes not only reinforce the ethical culture of a company but also attract people's attention to perceiving and observing social responsibility. This ultimately causes managers to combine society's expectations with the economic goals of organization in their decisions to ensure survival and long-term benefits.

\section{Ethical Consideration}

Ethical issues (such as plagiarism, conscious satisfaction, misleading, making and or forging data, publishing or sending to two places, redundancy and etc.) have been fully considered by the writers.

\section{Conflict of Interest}

The authors declare that there is no conflict of interests.

\section{Acknowledgement}

Researchers consider it necessary to thank and appreciate all the participants who helped us in this research.

\section{References}

1. Ashrafi J, Rahnamay Roodposhty F, Banimahd B (2019). Corporates social responsibility theories. Joumal of Management Accounting and Auditing Knowledge, 8(31): 1-14. (In Persian).

2. Leon Z, Don O, Myeong-Gu S, Madhu V (2021). Mood and ethical decision making: positive affect and corporate philanthropy. Journal of Business Ethics, 171 (1): 189-208. Doi: https://doi.org/10.1007/s10551-020-04432-5

3. Irannezhad Parizi M (1992). the social and ethical responsibilities of management. Journal of Management Knowledge, 18(1): 23-37. (In Persian).

4. Shen J, Zhang H (2019). Socially responsible human resource management and employee support for external CSR: roles of organizational CSR climate and perceived CSR directed toward employees. Journal of Business Ethics, 156 (3): 875-888. Doi: https://doi.org/10.1007/s10551017-3544-0

5. Carroll A (1979). A three-dimensional conceptual model of corporate social performance. Academy of Management Review, 4(1) :497-505. Doi: https://doi.org/10.5465/amr.1979.4498296

6. Carroll A (1991). The pyramid of corporate social responsibility: toward the moral management of organizational stakeholders. Business Horizons, 34(4): 39-48. Doi: https://doi.org/10.1016/0007-6813(91)90005-G

7. Ebrahimi L, Mansori A, Rahmani Ahmadabadi L (2014). A Survey on relationship between corporate social responsibility and respect for consumers rights (Case Study: Banking System in Bukan City). Joumal of Industrial Management. 9(30): 85-96. (In Persian).

8. Mirfallah-Nassiri R, Tojari F, Zarei A (2019). Investigating the factors affecting the ethical decision-making of

Available at: www.ijethics.com 
sports consumers. International Journal of Ethics \& Society (IJES), 1 (1):22-30.

9. Rahimi Kolour H, Eskandari N (2019). Relationship between social responsibility as an ethical factor and corporate image. International Journal of Ethics \& Society (IJES), 1 (3) : 47-57

10. Jabbarzadeh Kangarlue S, Fatehi S, Motavassel M (2016). Ethical ideology, corporate social responsibility with and information asymmetry in companies. The Financial Accounting and Auditing Researches, 8(31): 1-20. (In Persian).

11. Argandoña A (2016). Social responsibility and ethics in organizational management. Social Responsibility \& Health, 24(2): 13-19.

12. Harjoto M (2017). Corporate social responsibility and corporate fraud. Social Responsibility Joumal, 13(4): 762-779. Doi: https://doi.org/10.1108/SRJ-09-2016-0166

13. Ghasemzadeh A, Zavvar T, Mahdiuon R, Rezaee A (2014). Relation between professional ethics with social responsibility and individual accountability: mediating role of serving culture. Journal of Ethics in Science \& Technology, 9(2): 69 -76. (In Persian). Dor: http://dorl.net/dor/20.1001.1.22517634.1393.9.2.8.4

14. Talebi B, Seify Komar Sofla, A (2020). The relationship of professional ethics with social responsibility and organizational performance with the intermediation function of environmental performance in the general directorate of economic affairs and finance of east Azerbaijan. Joumal of Accounting and Management Vision, 2(18): 81-97. (In Persian).

15. Alizadeh S (2019). Canonical analysis of the relationship between components of professional ethics and dimensions of social responsibility . Journal of Ethics in Science \& Technology. 14 (1) :117-123. (In Persian). Dor:: http://dorl.net/dor/20.1001.1.22517634.1398.14.1.17.6
16. Simpson A (2017). Moral foundations theory: background, review, and scaffolding for future research. Encyclopedia of Personality \& Individual Differences, 1-20

17. Graham J, Haidt J, Koleva S, Motyl M, Iyer R, Wojcik S, Ditto P (2013). Moral foundations theory: The pragmatic validity of moral pluralism. Advances in Experimental Social Psychology, $\quad 47(2): \quad$ 55-130. Doi: https://doi.org/10.1016/B978-0-12-407236-7.00002-4

18. Aghababaei N, Talaei Pashiri A, Kwantes C (2017). Investigating the relations among personality characteristics, moral foundations, and work ethics in Iranian and Canadian students. Cultural Psychology, 1(2): 1-22. (In Persian). Dor: https://dorl.net/dor/20.1001.1.25887211.1396.1.2.1.0

19. Cranmer G, Martin M (2015). An examination of aggression and adaption traits with moral foundation. Communication Research Reports, 32(4): 360-366. Doi: https://doi.org/10.1080/08824096.2015.1089848

20. Malmir M (2019). Ethical and social consequences of dogmatism in society. International Journal of Ethics \& Society (IJES), 1(3): 5-9

21. Khayatmoghadam S (2020). The effect of professional ethics on the organizational culture. International Journal of Ethics \& Society (IJES), 2(1): 21-28

22. HaidtJ, Graham J (2007). When morality opposes justice: conservatives have moral intuitions that liberals may not recognize. Social Justice Researh, 20: 98-116.

23. Magner N, Welker RB, Campbell TL (1996). Testing a model of cognitive budgetary participation processes in a latent variable structural equation's framework. Accounting \& Business Researh, 27(1):41-50. Doi: https://doi.org/10.1080/00014788.1996.9729530

24. Moss E, Rousseau D, Parent S, St-Laurent D, Saintonge J (1998). Correlates of attachment at school age: maternal reported stress, mother-child interaction, and behavior problems. Child Development, 69(5):1390-405. Doi: https://doi.org/10.1111/j.1467-8624.1998.tb06219.x 